\section{JURNAL ABDIMAS

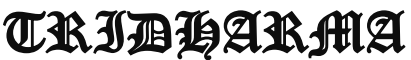

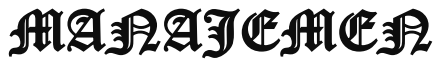

P-ISSN 2715-7105, E-ISSN 2716-070X

Jurnal ABDIMAS Vol. 2, No. 1, Januari 2021,Hal (9-14)

@ Prodi Manajemen Fakultas Ekonomi Universitas Pamulang

Email: abdimasjurnal.unpam@gmail.com Telp: (021) 741-2566

\title{
PEMANFAATAN LIMBAH RUMAH TANGGA SEBAGAI MEDIA BELAJAR PADA SD NEGERI PAMULANG PERMAI
}

\author{
Lismiatun, Fadillah, Ela Hulasoh Yusran Daeng Matta, Nindie Ellesia \\ Dosen Ekonomi Fakultas Ekonomi Universitas Pamulang
}

Email : dosen01460@unpam.ac.id,dosen02197@unpam.ac.id,dosen01910@unpam.ac.id ,dosen02331@unpam.ac.id,dosen02292@unpam.ac.id

\begin{abstract}
ABSTRAK
Tujuan dari Kegiatan Pengabdian Kepada Masyarakat adalah untuk melaksanakan salah satu TriDharma Perguruan Tinggi. Selain itu diharapkan dengan pengabdian kepada masyarakat tersebut keberadaan Perguruan Tinggi dapat memberikan kontribusi besar kepada pengembangan dan penerapan keilmuan kepada masyarakat.

Metode kegiatan yang digunakan adalah pelatihan pada tanggal 20-21 Juli 2020. Seminar dan pelatihan ini bertujuan agar siswa dan siswi dapat meningkatkan kreatifitas dan inovasi serta dapat memanfaatkan limbah rumah tangga untuk dijadikan media belajar.

Hasil pengabdian masyarakat yang diperoleh adalah bertambahnya keilmuan bagi para siswa dan siswi agar mereka memiliki pandangan yang baik tentang pentingnya memanfaatkan limbah rumah tangga.

Ilmu yang diperoleh pada Pengabdian Masyarakat kali ini diharapkan mampu memberikan semangat baru bagi kita dalam menyampaikan materi dan motivasi serta berkontribusi bagi generasi muda, baik dilingkungan sekolah, kampus, masyarakat dan keluarga.
\end{abstract}

Kata kunci : limbah rumah tangga, media belajar

\begin{abstract}
ABSTRAC
The purpose of Community Service Activities is to carry out one of the TriDharma of Higher Education. In addition, it is hoped that with this community service, the existence of Higher Education can make a major contribution to the development and application of science to the community.

The activity method used is training on July $20-21$, 2020. This seminar and training aims so that students can increase creativity and innovation and can use household waste to be used as learning media.

The result of community service that is obtained is the increase in knowledge for students and students so that they have a good view of the importance of utilizing household waste.
\end{abstract}




\section{JURNAL ABDIMAS

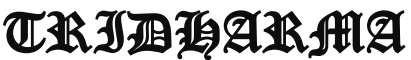

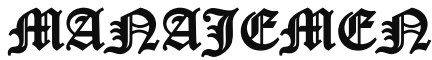

P-ISSN 2715-7105, E-ISSN 2716-070X

Jurnal ABDIMAS Vol. 2, No. 1, Januari 2021,Hal (9-14)

@ Prodi Manajemen Fakultas Ekonomi Universitas Pamulang

Email: abdimasjurnal.unpam@gmail.com Telp: (021) 741-2566

The knowledge obtained at this Community Service is expected to be able to provide new enthusiasm for us in conveying material and motivation as well as contributing to the younger generation, both in the school, campus, community and family environment.

\section{Keywords: household waste, learning media}

\section{PENDAHULUAN}

Masalah lingkungan merupakan masalah yang timbul dari manusia sendiri, maka penanggulangannya ditentukan oleh perilaku hidup manusia yang ramah lingkungan. Upaya yang harus segera kita lakukan salah satunya melalui proses pendidikan. Terkait dengan masalah lingkungan yang makin hari makin bertambah banyak dan beragam tersebut maka dianjurkan untuk sekolah menerapkan manajemen atau pengelolaan sekolah berbasis adiwiyata. Salah satu caranya adalah dengan menciptakan sekolah ramah lingkungan dengan menciptakan kesadaran untuk memanfaatkan sampah. Karena Sekolah memiliki peran untuk mengembangkan masyarakat yang sadar lingkungan, dan meningkatkan kecerdasan ekologis ini. Sekolah berperan bukan hanya sebagai tempat belajar tetapi juga memiliki peran penting untuk membantu siswa dalam memahami akibat perilaku manusia di bumi dan menjadi tempat untuk hidup secara berkelanjutan.

Dengan adanya media pembelajaran guru dapat menyampaikan materi dengan maksimal dan efesien kepada siswa, apalagi pada pendidikan tingkat Sekolah Dasar yang mayoritas siswanya terdiri dari anak yang berusia 6-11 tahun, maka dibutuhkanlah sebuah media yang dapat menarik prestasi belajar mereka untuk tercapainya tujuan pembelajaran. Penggunakan media pembelajaran dalam kegiatan belajar mengajar akan meningkatkan motivasi dan membantu mempermudah pemahaman peserta didik terhadap materi sehingga menciptakan pembelajaran yang bermakna. Seorang guru harus memiliki kemampuan dalam menciptakan media pembelajaran yang inovatif sehingga dapat meningkatkan pemahaman dan motivasi belajar peserta didik. Media pembelajaran sebagai alat bantu dalam kegiatan pembelajaran dapat dikembangkan secara sederhana dari beberapa sampah yang ada di lingkungan sekitar.

Dalam pemanfaatan limbah rumah tangga di SD Negeri Pamulang Permai meliputi beberapa aspek yaitu, mengenal jenis limbah rumah tangga antara organik dan anorganik serta dapat memanfaatkan sampah organik yang dapat dijadikan media belajar. Karena hal yang penting untuk di pelajari oleh anak semenjak dini adalah literasi.

\section{RUMUSAN MASALAH}

Berdasarkan permasalahan utama yang di jelaskan pada latar belakang yang telah dijelaskan sebelumnya, maka solusi yang ditawarkan adalah memberikan pengarahan dan pelatihan terhadap siswa dapat mengetahui limbah rumah tangga organik atau non organik yang ada di lingkungan rumah ataupun sekolah, siswa dan siswi dapat membedakan sampai sesuai dengan klasifikasinya serta dapat memanfaatkan limbah tersebut menjadi media pembelajaran.

Banyak manfaat lain yang diperoleh dari pemanfaatan limbah bekas rumah tangga yang dapat dijadikan media belajar bagi para siswa dan siswi agar merangsang motorik, ide dan kreatifitas yang lebih baik bagi para siswa dan sisi khususnya di SD Negeri Pamulang Permai, serta para guru dapat mengembangkan cara-cara, metode dan inovasi yang lebih kreatif dan menarik sehingga para siswa senang dan tertarik 


\section{JURNAL ABDIMAS

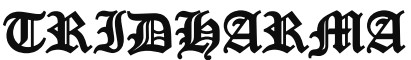

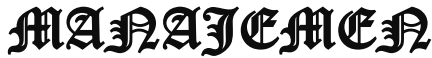

P-ISSN 2715-7105, E-ISSN 2716-070X

Jurnal ABDIMAS Vol. 2, No. 1, Januari 2021,Hal (9-14)

@ Prodi Manajemen Fakultas Ekonomi Universitas Pamulang

Email: abdimasjurnal.unpam@gmail.com Telp: (021) 741-2566 untuk mengikuti proses pembelajaran di sekolah ataupun di rumah.

\section{TUJUAN PELAKSANAAN}

Sejalan dengan hal tersebut maka pentingnya sosialiasai pemanfaatan limbah rumah tangga periode anak sekolah dasar yang dianggap mulai bertanggung jawab dan memperoleh keterampilan tertentu salah satu diantaranya membuat media belajar. Oleh karena itu kami melihat penting untuk memberikan pemahamaan terhadap sampah yang dapat dijadikan media belajar dapat membentuk karakter dari anak untuk peduli terhadap lingkungan dan dapat meningkatkan kreatifitas pada anak.

\section{TINJAUAN PUSTAKA}

\section{Pengertian Limbah}

Limbah adalah buangan yang kehadirannya pada suatu saat dan tempat tertentu tidak dikehendaki lingkungan karena tidak memiliki nilai ekonomis. Limbah merupakan salah satu penyebab pencemaran lingkungan yang membawa dampak buruk bagi kesehatan masyarakat. Limbah digolongkan kedalam 2 (dua) kelompok yaitu limbah rumah tangga dan limbah industri.

Berdasarkan wujud limbah yang dihasilkan, limbah terbagi 3 yaitu:

1. Limbah padat

Limbah padat adalah limbah yang memiliki wujud padat yang bersifat kering dan tidak dapat berpindah kecuali dipindahkan. Limbah padat ini biasanya berasal dari sisa makanan, sayuran, potongan kayu, ampas hasil industri, dan lainlain.

\section{Limbah gas}

Limbah gas adalah limbah yang berwujud gas. Limbah gas bisa dilihat dalam bentuk asap dan selalu bergerak sehingga penyebarannya luas. Contoh dari limbah gas adalah gas buangan kendaraan bermotor, buangan gas dari hasil industri.

3. Limbah cair

Limbah cair adalah limbah yang memiliki wujud cair. Limbah cair ini selalu larut dalam air dan selalu berpindah (kecuali ditempatkan pada wadah/bak). Contoh dari limbah cair ini adalah air bekas cuci pakaian dan piring, limbah cair dari industri, dan lain-lain.

\section{Pengertian Limbah Rumah Tangga}

Berdasarkan Keputusan Menteri Negara Lingkungan Hidup No. 112 Tahun 2003 yaitu limbah domestik adalah air limbah yang berasal dari usaha dan atau kegiatan permukiman (real estate), rumah makan (restaurant), perkantoran, perniagaan, apartemen dan asrama.

Sebenarnya limbah dapat dikelola dan dimanfaatkan, misalnya bekas bungkus minuman kemasan dapat dimanfaatkan menjadi kerajinan tangan bagi yang memiliki kreatifitas tinggi, kemudian bekas bungkus detergen dapat dijadikan sebagai media tanam pengganti polybag.

Pada sekarang ini manfaat bagi sebahagian besar limbah rumah tangga dapat disosialisasikan kepada setiap warga dengan harapan dapat diajarkan dan dipraktekkan secara langsung. Agar dengan proses ini di harapkan agar masyarakat menya dari pentingnya pengolahan limbah rumah tangga menjadi produksi yang lebih bernilai ekonomis. Limbah rumah tangga dapat di jadikan sebagai pupuk alami untuk tanaman hortikultura.

\section{Pengertian Limbah Teh}

Sama dengan halnya limbah tahu, teh basi yang dihasilkan oleh rumahan, air teh basi yang selama ini hanya dibuang ternyata bermanfaat bagi kesuburan tanaman, bahwa air teh basi dapat menyuburkan tanaman dan bahwa tanaman yang disiram dengan air teh basi, pertumbuhannya lebih baik dibandingkan dengan tanaman yang tidak diberi air teh basi. Hal tersebut menunjukkan bahwa 


\section{JURNAL ABDIMAS

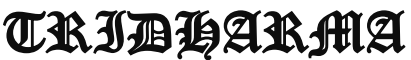

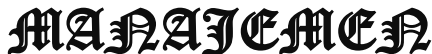

P-ISSN 2715-7105, E-ISSN 2716-070X

Jurnal ABDIMAS Vol. 2, No. 1, Januari 2021,Hal (9-14)

@ Prodi Manajemen Fakultas Ekonomi Universitas Pamulang

Email: abdimasjurnal.unpam@gmail.com Telp: (021) 741-2566 sebagai limbah rumah tangga, air teh basi dapat dimanfaatkan sebagai pupuk bagi tanaman.

Teh mengandung senyawasenyawa bermanfaat seperti poliefenol, tehfllin, flavonoid, tanin, vitamin $\mathrm{C}$ dan vitamin $\mathrm{E}$ serta sejumlah mineral $\mathrm{Zn}, \mathrm{Se}$, $\mathrm{Mo}, \mathrm{Ge}$ dan Mg. Kandungan teh yang berupa mineral tersebut merupakan unsurunsur esensial yang sangat dibutuhkan oleh tanaman. Air teh basi bermanfaat memperbaiki kesuburan tanah, merangsang pertumbuhan akar, batang dan daun.

\section{METODE PELAKSANAAN}

Kegiatan yang dilakukan lebih kepada interaktif kepada pada siswa/i dengan memberikan arahan, bimbingan, tanya jawab bagaimana cara-cara yang paling mudah untuk dilakukan para siswa/i dalam pengambilan keputusan.

Sebelum kegiatan berlangsung tim pengabdian melakukan tahap sosialisasi terlebih dahulu yaitu melakukan silaturahmi dengan Ketua Yayasan, menyampaikan maksud dan tujuan pengabdian ini, sekaligus untuk menjalin kerjasama serta menentukan jadwal kegiatan pengabdian. Pelaksana kegiatan pengabdian pada masyarakat adalah Dosen Universitas Pamulang Fakultas Ekonomi Program Studi Manajemen sebanyak 5 orang dosen dan diikuti oleh para siswa/i dengan jumlah sebanyak 51 orang siswa serta guru-guru pendamping sebanyak 5 orang.

Kegiatan pengabdian kepada masyarakat dilakukan dengan metode sebagai berikut :

1) Identifikasi masalah yang dilakukan sebagai langkah awal untuk merumuskan apa saja yang akan dijadikan bahan untuk perancangan system dan materi pelatihan dalam kegiatan pengabdian ini.

2) Melakukan survey lapangan ke Sekolah SDN Pamulang Permai sebagai tempat dilaksanakannya kegiatan kemudian melakukan proses wawancara dan diskusi dengan pihak sekolah untuk identifikasi permasalahan yang ada dalam lingkungan siswa intra sekolah.

3) Kontribusi pengusul dalam proses pengabdian dengan melakukan penelitian pustaka untuk acuan materi yang digunakan selama kegiatan pengabdian.

Pelatihan ini bertujuan agar siswa dan siswi SD Negeri Pamulang Permai dapat memanfaatkan limbang dari lingkungan keluarga menjadi media pembelajaran untuk tercapainya tujuan pembelajaran.

\section{HASIL DAN PEMBAHASAN}

Berdasarkan wawancara, tanya jawab dan pengamatan langsung selama kegiatan berlangsung, kegiatan pengabdian pada masyarakat ini memberikan hasil sebagai berikut :

1. Memberikan pengetahuan kepada siswa dan siswi mengenai pemanfaatan limbah rumah tangga sebagai media belajar

2. Memberikan pengetahuan kepada siswa dan siswi agar menciptakan media belajar yang bagus agar lebih mudah tercapainya tujuan pembelajaran.

3. Memberikan gambaran dan pengetahuan kepada siswa dan siswi SDN Pamulang Permai mengenai cara menciptakan atau mengolah limbah rumah tangga menjadi bahan belajar.

Beberapa faktor yang mendukung terlaksananya kegiatan pengabdian pada masyarakat ini adalah besarnya minat dan antusiasme peserta selama kegiatan, sehingga kegiatan berlangsung dengan lancar dan efektif. Sedangkan faktor penghambatnya adalah keterbatasan waktu pelatihan dan fasilitas peralatan yang masih minim. 


\section{JURNAL ABDIMAS

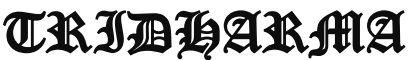

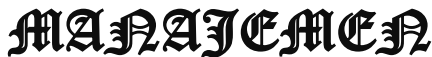

P-ISSN 2715-7105, E-ISSN 2716-070X

Jurnal ABDIMAS Vol. 2, No. 1, Januari 2021,Hal (9-14)

@ Prodi Manajemen Fakultas Ekonomi Universitas Pamulang

Email: abdimasjurnal.unpam@gmail.com Telp: (021) 741-2566

\section{KESIMPULAN DAN SARAN}

\section{Kesimpulan}

Dari kegiatan pengabdian pada masyarakat ini dapat disimpulkan bahwa:

Pengetahuan dan pemahaman siswa dan siswi SD Negeri Pamulang Permai tentang pemanfaatan limbah rumah tangga dan sekitar lingkungan sebagai media belajar yang menyenangkan dan menarik.

Semakin meningkatnya ide dan kreatifitas dalam mengembangkan metode-metode pembelajaran dengan media limbah bekas rumah tangga.

\section{Saran}

Mengingat besarnya manfaat kegiatan pengabdian pada masyarakat ini, maka selanjutnya perlu:

1) Mengadakan sosialisasi dan pelatihan serupa pada siswa sekolah lain di kecamatan yang lain, dengan materi yang serupa.

2) Adanya kesinambungan program pasca kegiatan pengabdian ini sehingga para siswa benar-benar dapat memanfaatkan limbah rumah tangga menjadi media belajar.

\section{DAFTAR PUSTAKA}

$\begin{array}{lcr}\text { Adinugraha, } & \text { Fajar.(2017). } & \text { Media } \\ \text { Pembelajaran } & \text { Biologi } & \text { Berbasis } \\ \text { Ecopreneurship } & & \end{array}$

Kardong Eddy dan Sontang Manik. 2003. Pengelolaan Lingkungan Hidup. Jakarta: Djambatan.

Ma'ruf, A. \& Mahmudiyah, L. (2016).Penggunaan Media Limbah Bungkus Sabun Mandi Untuk Meningkatkan Prestasi Belajar Pendidikan
Agama Islam Di SDN Sumberanyar 1 Pasuruan.Jurnal Studi Islam, 1, (2).

Nurlail ,Shofiyatun. PENGENALAN ECOLITERACY MELALUI MEDIA PEMBELAJARAN DARI SAMPAH DI SEKOLAH DASAR.

Pasaribu, V. L. D., Susanti, F., \& Hartuti, E. T. K. (2019). Memotivasi Siswa dan Siswi SMK Letris Indonesia di Dalam Menentukan Pilihan Untuk Melanjutkan Pendidikan Atau Bekerja Setelah Lulus Sekolah. Jurnal Pengabdian Dharma Laksana, 1(2), 161-172.

Pasaribu, V. L. D., Agrasadya, A., Shabrina, N., \& Krisnaldy, K. (2020). MENJADI ENTERPRENEUR MUDA YANG MEMILIKI JIWA LEADERSHIP UNTUK MENGHADAPI MASA DEPAN. Abdi Laksana, 1(1).

Pasaribu, V. L. D., Elburdah, R. P., Sudarso, E., \& Fauziah, G. (2020). PENGGUNAAN MANAJEMEN WAKTU TERHADAP PENINGKATAN PRESTASI BELAJAR DI SMP ARAISIYAH. Jurnal ABDIMAS Tri Dharma Manajemen, 1(1).

Pasaribu, V. L. D., Sulaiman, S., Sutiman, S., Thaharudin, T., \& Purnomo, B. Y. (2020). PENGENALAN LETAK POSYANDU TERDEKAT DIKELURAHAN PISANGAN DENGAN MANAJEMEN PEMASARAN REVOLUSI $\quad 4.0 \quad$ UNTUK MENINGKATKAN PENGETAHUAN MASYARAKAT LETAK DAN FUNGSI POSYANDU TERDEKAT PADA KELURAHAN PISANGAN. DEDIKASI PKM, 1(1), 105-110.

Pasaribu, V. L. D., Oktrima, B., Prabowo, B., Arianto, N., \& Haryoko, U. B. (2020). PROGAM PENDAMPINGAN DAN PENYELENGGARAAN PENDIDIKAN ANAK PADA USIA DINI TERHADAP 


\section{JURNAL ABDIMAS

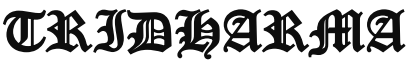

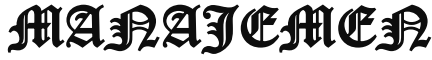

P-ISSN 2715-7105, E-ISSN 2716-070X

Jurnal ABDIMAS Vol. 2, No. 1, Januari 2021,Hal (9-14)

@Prodi Manajemen Fakultas Ekonomi Universitas Pamulang

Email: abdimasjurnal.unpam@gmail.com Telp: (021) 741-2566

PRESTASI BELAJAR DILINGKUNGAN

RT 020 RW 009. KEL GIRI PENI. KEC

WATES. YOGYAKARTA. JURNAL

LOKABMAS KREATIF, 1(1), 71-75.

\section{DOKUMENTASI FOTO KEGIATAN}

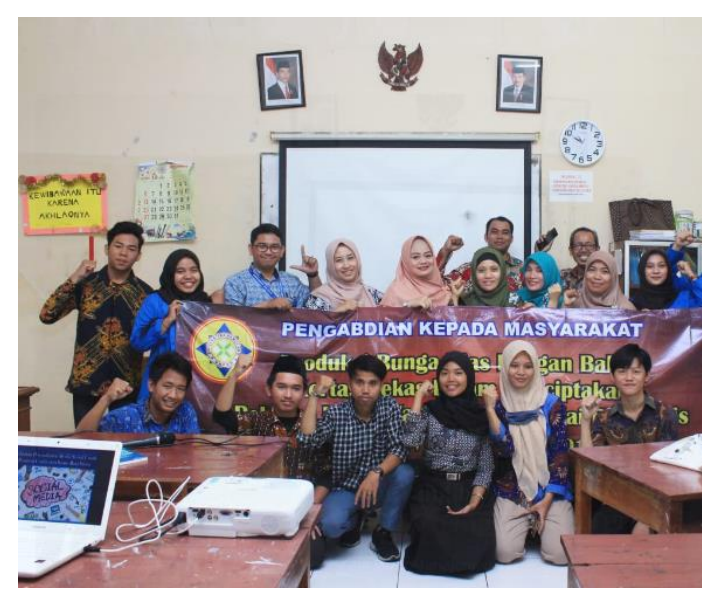

